\title{
Critical Review of Pipeline Scale Measurement Technologies
}

Paul Rostron*

Department of Chemistry, Institute of Petroleum, Khalifa University of Science and Technology P.O Box 2533, Abu Dhabi, UAE; prostron@pi.ac.ae

\begin{abstract}
Objectives: To review current and potential methods to identify scale, either wax, inorganic or corrosion deposits on the internal side of pipelines. Methods/Statistical Analysis: The study presents a literature review of the possible approaches for scale detection, using NDT approaches. Findings: We were able to review 94 papers on scale detection; this represents the complete literature on the subject. Application/Improvements: This paper serves as a single source of all potential methods of identifying pipeline scales.
\end{abstract}

Keywords: Corrosion, Pipeline Scale, 5Review, NDT

\section{Introduction}

Oilfield scale deposits usually consist of inorganic deposits along with some organic deposits (wax deposition, hydrate formation, asphaltine deposition) or corrosion deposits and can be found in many locations, such as pipe walls, valves, downhole equipment and pumps ${ }^{1}$. Chemically, scale deposition is the crystalline precipitate of mineral compounds formed in water ${ }^{2}$. In the presence of wax, oil, gas or corrosion products in pipelines, the formed scale would contain more than one mineral because of the trapped wax and iron oxide during the scale formation ${ }^{3}$.

Several mechanisms are raised to explain scale deposit and one of which is auto scaling. Scale appears as minerals starting to precipitate when the concentration of mineral exceeds its saturation limit. This could be caused by the change of some physical properties of fluid (usually water) such as pressure, temperature and $\mathrm{pH}^{4}$. Another mechanism is the incompatible mixing when two fluidsmix together and the ion concentration rises above solubility limits. Two fluids mixing usually happen in process like enhanced oil recovery operations where the sea water is injected and this interacts chemically with the formation water ${ }^{5}$. The greatest threat to trigger carbonate precipitation is fresh water. When the total dissolved solids are low, carbonates are less soluble and precipitation occurs 5 .

The formation of the salt crystal is based on nucleation growth. The nucleation process is called homogenous nucleation if the scale starts to grow from supersaturation solution. The ions and atom pairs to form small crystal seed, which grow by adsorbing more ions onto the imperfect surface of the crystal seed. Heterogeneous nucleation happens when the crystals are initiated on existing surface which have a defect or rough spots. This explains why older, more corroded, and hence rougher pipes seem to get more scaling.

In oil and gas industry, the most common scale is carbonate (calcium carbonate, siderite), sulfate (barium sulfate and calcium sulfate) and halite (Table 1$)^{6}$.

Calcium carbonate, which also known as calcite scale is generally formed by the auto scaling process. The formation of calcite scale happens when the carbon dioxide lost from the water (degassing) as the following reaction ${ }^{7}$ :

${ }^{*}$ Author for correspondence 


\begin{tabular}{|l|l|}
\hline $\begin{array}{l}\text { Table 1. Most common scale deposits in oil and gas } \\
\text { pipelines }\end{array}$ \\
\hline Minerals & Formula \\
\hline Calcite & $\mathrm{CaCO}_{3}$ \\
\hline Anhydrite & $\mathrm{CaSO}_{4}$ \\
\hline Halite & $\mathrm{NaCl}$ \\
\hline Barite & $\mathrm{BaSO}_{4}$ \\
\hline
\end{tabular}

$$
\mathrm{Ca}^{2+}+2 \mathrm{HCO}_{3}^{-} \rightleftharpoons \mathrm{CaCO}_{3} \downarrow+\mathrm{CO}_{2}+\mathrm{H}_{2} \mathrm{O}
$$

Also, calcium carbonate solubility increase when the temperature increase whiles the pressure of the carbon dioxide is constant in the water.

Groundwater with a high content of calcium and sulfate will be a driving force to form anhydrite or gypsum scale when it combined with formation water and injected in the process (incompatible mixing) ${ }^{8}$.

Sodium chloride scale (halite) experiences an auto scaling process when there is a large drop in the temperature of water with a fast rate of deposition leading to many tons of scale everyday (20 IBM for each barrel of water produced) ${ }^{9}$.

Barium sulfate scale results from the mixing of incompatible water (sulfate bearing water) with high barium content reservoir fluids and reach above the saturation level; it will combine with sulfate ion and barite scale will deposit $^{10}$.

$$
\mathrm{Ba}^{2+}+\mathrm{SO}_{3}^{2-} \rightarrow \mathrm{BaSO}_{4} \downarrow
$$

Especially in gas pipelines, black powder is the most common solid contaminant through the world ${ }^{11}$. Its composition differs from different situations and can be considered as the mixture of either iron sulfides, carbonates, hydroxides or oxides which probably came from scales, corrosion products, rust, salts or mill-scale ${ }^{12,13}$.

There are two basic ways of scale solids present in pipelines: suspending in aqueous solution or adhering to the pipe surface ${ }^{14}$. And the continuous growth of the scale crystal can cause series of problems such as formation plugging accounted for suspended scale or flow restriction by adherent deposits which could block and damage production line or any safety valve. Also, it increases wall roughness and that will lead to the increase of frictional pressure. As a result, the production rate will be reduced and eventually the well will be abandoned ${ }^{15}$. The uncontrolled scale deposition can even lead to potential economic disaster. For instance the incident happened to of one the North Sea wells in the Miller Field, where the oil production dropped from 30 thousand barrels per day to zero within 24 hours $^{16}$.

Thus it's essential to remove scale and remediation techniques must be fast and not damage or affect the pipeline. Scale deposition can be controlled by chemical or mechanical methods. A chemical method like the injection of scale inhibitors or chemical dissolution where a reagent or acids are injected through a pipeline to dissolve some of scale precipitated in pipe walls ${ }^{17}$. Mechanical remediation methods are one of the best treatment methods to remove scale because it's less expensive than other methods and at the same time efficient. Mechanical cleaning method such as wire brushing, milling, and explosive or jet blaster tools where the nozzle heads are rotated to scrape the deposit from the pipeline covering a large diameter across the pipe ${ }^{9}$. The success of the removal techniques depends on using the suitable techniques for the correct scale. To select the best techniques for the particular pipeline, it's important to know information about the scale such as the composition, texture, quantity and thickness prior to the application of the technique. Therefore, it's important to use monitoring and detection techniques to determine scale present, types and location.

There are several techniques that are developed for detecting and identifying scale as will be discussed in this review.

\section{Conventional, Geochemical and Petrography Methods}

Most current industry practice depends on monitoring scale and corrosion in the pipeline through simple techniques such as offline chemical analysis of the produced water or brine, inhibitor residual, total suspended solids or static bottle tests ${ }^{18-20}$. In regard to water chemistry analysis, ion concentration is normally taken into account. For example, a sharp decline in some scale ions such as $\mathrm{Ca}^{2+}$ may indicate the starting of scale forming 9 . Detection of the residual scale inhibitor's concentration is another indirect means. When there is a drop in inhibitor concentration, potential scaling can occur since the missing inhibitor adhered to scale particles. All these meth- 
ods are used due to their low cost, availability and ease of application. Consideration should be made in dealing with such tools because it has many limitations that can hinder accurate identification or lead to overestimation of the actual situation of scale deposition. The main issue is that this offline samples may not be representative of the whole pipeline situation. Other concerns are regarding to the stability of the samples with time. Until the samples are analyzed in the lab it can be subject to deterioration and compositional change due to scale precipitation and dissolved gas evolution such as $\mathrm{CO}_{2}{ }^{18}$. Such wrong estimation can be costly either by unnecessary chemical and inhibitor consuming or by untreated scale consequences.

Another alternative practice by many pipeline operators is to use pigging return as indication of any scale presence $^{20,21}$. Visual inspection can be used to identify any sign for scale presence. For example, scale deposition in the pipeline can be expected when there is a drop in production, or decrease in the flow rate. Also, an increase in pressure drop can be monitored ${ }^{18-20}$. It should be mentioned that these indicators are not only caused by scale, so they are not conclusive. Also, the main idea behind early detection is to avoid any of these problems from happening. Another method for physical inspection is based on removing a section of pipeline to measure the scale thickness and analyzing the scale through different analytical techniques. There are a wide variety of analytical methods to analyze the scale composition from the obtained samples $^{22}$. For example, FT-IR spectroscopy is useful in organic scale while X-ray fluorescence is used to identify amorphous and inorganic deposits. Although these techniques are useful and accurate, it is still doubtful as it is subject to sampling method, skill of the analyzer and the frequency of inspection ${ }^{20}$. In addition, the time consumed can be critical in many pipelines as scale increase have been reported to stop production within 24 hours 9 . All these methods indicate the necessity to develop in-situ analysis techniques to allow early detection.

\section{Electrochemical Techniques}

The use of electrochemical techniques has been described as an offline method to manage and monitor scale deposition in bulk solution. Among the reported techniques are thickness shear-mode resonator, rotating disc electrode and conductiometric scaling potential test. Different important information can be collected from these techniques which in turn help in optimizing the required treatment and inhibitors selection; however none of these methods are commonly practiced.

\subsection{Thickness Shear-Mode Resonator (TSMR)}

Thickness shear-mode resonator (TSMR) is a method that determines the stability of brine/produced water toward the scale formation in oil pipelines ${ }^{17,19}$. TSMR is composed of a piezoelectric wafer sandwiched between two thin metal electrodes ${ }^{17}$. The shear deformation that is formed when an electrical potential is applied, is characteristic to the particular wafer. This technique is mainly based on using a piezoelectric mass sensor to detect the change in resonance frequency caused by scale deposition. It is convenient and have advantages over other techniques based on residual inhibitor or water chemistry which has been proven inadequate and can give false indication compared to real field situation. This technique has been previously used with quartz crystal microbalances in vapor phase metal deposition, but was not applicable for liquid phase measurement due to the interference caused by the resonate dumping. TSMR oscillator circuitry has over-come this limitation by measuring the frequency derived mass data after correcting with respect to resonator damping output. Some field trials have been conducted using TSMR techniques such as the field study conducted by D.H. Emmons at North Sea offshore platform ${ }^{19}$. The method showed good results that can be used to optimize scale treatment saving operating costs.

In general, determining the stability of scaling brine using TSMR can yield accurate, rapid measurement using a robust small size instrument. It has potential to be used as near real time monitoring techniques, both onshore and offshore. Also, it showed high sensitivity in detecting scale deposition in the range of nanograms $s^{17,19,20}$. Despite all these advantages, TSMR technique still not ready to be used in real applications as it suffers from several drawbacks that should be thoroughly considered. For example, fast saturation and loading limit of the sensor can render it ineffective for continuous monitoring ${ }^{19}$. The applicability is limited by the presence of other materials such as oil, corrosion inhibitor and sand as it can result in wrong readings ${ }^{19,20}$. It should be mentioned that TSMR is a point measurement and can only measure the scale adherent to the surface but not the dispersed scale. 


\subsection{Rotating Disc Electrode Method}

Rotating disc electrode is another electrochemical technique for scale monitoring as a function of time. It is based on the oxygen reduction reaction and Levich's equation (Equation 1 and 2 respectively) $)^{23,24}$.

$$
\begin{array}{ll}
\mathrm{O}_{2}+2 \mathrm{H}_{2} \mathrm{O}+4 e^{-} \rightarrow 4 \mathrm{OH}^{-} & \text {(Equation 1) } \\
i_{L}=0.62 n F A D^{2 / 3} \omega^{1 / 2} \gamma^{-1 / 6} \mathrm{C} & \text { (Equation 2) }
\end{array}
$$

Where: $i_{L}$ is the limiting current, $n$ is the number of electrons in half reaction, $F$ is Faraday constant, $A$ is the area of electrode, $D$ is the diffusion coefficient, $\omega$ is the rotation rate of the electrode $\gamma$ is the kinematic viscosity and $C$ is the concentration of analyte. According to Levich's equation and under mass control condition, an applied constant potential in rotating disc electrode will result in proportional relation between the limiting current and the square root of the rotational speed ${ }^{23}$. The extent of surface scale deposition is determined in these techniques by assessing the reduction in the active surface area of the electrode and the change in oxygen reduction caused by the scale formation ${ }^{20,24}$. The potential of this electrochemical technique in determining scale intensity has been reported in some initial trials as a promising in-site and online monitoring techniques. For example, Morizot and his team applied this technique in investigating the formation rate of two kinds of scale; $\mathrm{BaSO}_{4}$ and $\mathrm{CaCO}_{3}$ on the surface of stainless steel electrode ${ }^{24}$. The results of such method were validated by comparison with results from image analysis. There are a number of assumptions that should be considered in RDE analysis. It assumes that scale deposit prevents oxygen transport and cannot re-dissolve once it is precipitated. In addition, it assumes an oxygen reduction happen at a constant rate during analysis and $i_{L}$ and $\omega^{1 / 2}$ is linear ${ }^{23}$. It can be seen that this technique requires a lot of further investigation and field trials to ensure its future applicability ${ }^{24}$. Also, one of the key RDE limitations that should be overcome is the inaccuracy in the presence of oil or dissolved species similar to TSMR techniques.

\subsection{Conductiometric Scale Potential Test}

Conductiometric scale potential test is an electrochemical tool that can yield quantitative information regarding scale prediction and amount of scale precipitation ${ }^{25}$. Some research has shown the efficiency of such technique in optimizing scale inhibitor dosage. This method consists of measuring the change in specific resistivity of the analyzed brine. Conductiometric test was reported in determining $\mathrm{CaCO}_{3}$ scaling potential in oilfield brine. This method is not very common and the result depends on the analyzed produced water which cannot be conclusive.

\section{Sensors}

\subsection{Fiber Optics}

Optical fibers are flexible, transparent dielectric fiber consist of solid core surrounded by transparent cladding material of lower refractive index guiding the light wave through the core. There is a broad wavelength range of light source can be used from UV, VIS, near-IR to mid-IR. Figure 1 is schematic of the exposed fiber optic detection principle ${ }^{4}$. The sensor has a removed section of cladding part where the light can be totally reflected inside the core. When scale deposits on the exposed fiber surface, part of the guided light will be absorbed by the scale crystal instead of reflecting back into the core part due to the higher refractive index than fiber core. Thus a reduction in radiation transmitted through the end of the fiber can be measured and used to estimate the formation of heterogeneous scale ${ }^{26}$. Using the exposed core optical sensor was first proposed by Philip Chandy for measuring silver chloride crystal formation ${ }^{27}$.

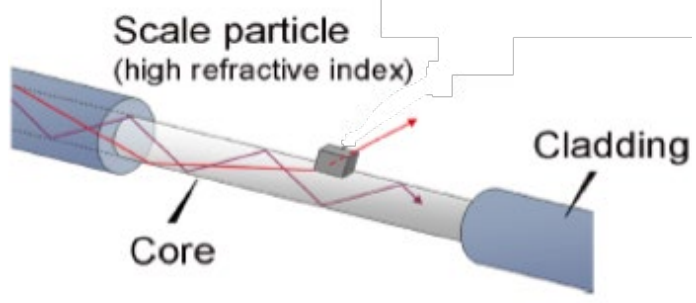

Figure 1. Exposed core optical fiber sensor for scale detection $^{4}$.

Some system used exposed section of optical core when it in inserted in solution with lower refractive index to provide information about heterogeneous crystallization ${ }^{28}$. An intrinsic exposed core optical fiber sensor (IECOFS) is used by $\mathrm{M}$ Boerkamp to study $\mathrm{CaCO}_{3}$ scale crystal growth on fused silica core and poly-methyl-methacrylate (PMMA) core ${ }^{29}$. IECOFS is a powerful, reliable 
and sensitive tool for only heterogeneous crystallization process. It is found that the optical attenuations to be linearly associated with the thickness of the scale layer. Takuya Okazaki ${ }^{4}$ conducted fiber optic evanescent wave sensor with different core diameters and revealed that the smaller fiber core diameter gave higher sensitivity to the detection system. A satisfying result was gained when evaluating the sensor's performance in field test of nature geothermal water.

The optical fiber is also used as corrosion sensor. The un-cladded part which is the sensitive part of the optical fiber corrosion sensor is covered with nickel-phosphorus deposit by electrolysis method for $2 \mathrm{~cm}$ length. The transmitted light through fiber is recorded as a function of the angle of incidence of the light emitted by the laser diode at $670 \mathrm{~nm}$ wavelength ${ }^{30}$. The increase in the corrosion intensity can be detected by the increase in the full width of the recorded curves at half maximum. The corrosion sensor can be inserted in the pipeline structure to give in-situ information.

Optical fibers are cheaper systems in monitoring inorganic scale crystal formation in low refractive index aqueous solution and easy to reduce its size with simple modification ${ }^{30}$. It seems to be more capable to monitor scale formation than other scale sensing methods like turbidity measurement or electrical conductivity of the solution. The sensor has the ability to distinguish between surface (scale formation) and bulk crystallization and quantify deposition on a given surface while the turbidity measurement depends on the optical transparency of the solution and the electrical conductivity of the solution depend on the ion concentration in the solution.

\subsection{Attenuated Total Reflectance Spectroscopic Sensor}

Attenuated total reflectance (ATR) probe is a direct surface analysis technique known as scale sensor. It is a simple and cost effective monitoring techniques based on existing technology and just need little supporting equipment ${ }^{18}$. Similar to optical fiber, at a certain angle when the incident light strikes the ATR crystal-sample surface, total reflection would happen. Most of the incident light reflected back into the crystal while the small portion transferred back to the sample medium or to the surface of the crystal. The spectroscopic sensor will directly measure the energy loss of the incident light and the change of the refractance of the material in contact with the surface of the probe. It is important to select a suitable probe material for the ATR according to the condition or the environment where it will be used ${ }^{31}$. For example, it's better to use a probe made of sapphire in a corrosive condition to avoid any decomposition in the probe. Also, it's good to know that the scale sensor is not affected by any suspended solids, $\mathrm{pH}$ or the crude oil present in the production fluids ${ }^{2}$. ATR is very capable to detect severe calcium carbonate scale with the help of suitable computer programs but unable to distinct scale types.

\subsection{Heat based Sensor}

In the presence of scale deposit on the pipe wall, a decrease in heat flow rate in the scaled formation location can be observed. This is because the thermal conductivity of scale is lower than steel walls ${ }^{1}$. Based on this concept, heat based sensor is developed to estimate scale formation by measuring the temperature changing through a temperature sensor ${ }^{32}$ or the decline in the heat transfer coefficient ${ }^{26}$. The late method needs a heated solution which means it is not suitable for scale monitoring if there is no change in the heat in the system.

Distributed temperature sensor (DTS) is used in oil and gas industry to give real time monitoring of the temperature of the produced fluid. In $^{1}$ applied this technique in studying the scale deposition in a conventional producing wall. By determining DTS depth-temperature profile data, presence of scale was detected and scale thickness as well as inside radius of scaled area could also be estimated through an algorithm.

Permanent sensors are installed downhole for monitoring and constant reservoir surveillance purpose. The sensor can detect potential problems in wells and pipelines by continues delivery of different data like change in temperature, vibration or current leakage. The experience and the long term of using downhole sensor ensure that the technology is capable to give reliable transmission data and longer sensor life. Scale deposit reduces carbon dioxide injectivity into the reservoir. In a laboratory investigation done by team a combined data of temperature and resistivity were used to detect dissolution of carbonates and the formation of scale in real time ${ }^{33}$. The advantages of this method are that it doesn't require a new installation of equipment and the already installed permanent sensor can be used with high accuracy and cost 
reduction were no supportive equipment is needed. The limitation of this study is that it hasn't been used in the presence of oil or been applied in real pipelines.

\subsection{Other Types of Sensors}

Other commonly used sensors are electrical conductivity and turbidity measurements $s^{34,35}$. However, these techniques are easily affected by the presence of non-scale forming ion in the solution ${ }^{36}$. Other scale sensors can detect the change in the radioactivities which indicate the formation of some radioactive salt scale like radium salt scale $^{32}$.

\section{Ultrasound Technique}

Ultrasonic detection techniques are a common method used to measure pipes wall thickness and is developed to detect the presence of scale. This technique depends on measuring the velocity of the sound reflected and when testing, a diagnostic machine which pass over the inspected pipe an ultrasound transducer is connected ${ }^{37}$. The incident ultrasonic wave faces the interface, which will be represented by the energy reflection of the incident wave. The most important information is the difference in the amplitude of the reflected wave relative to the actual incident wave which is a function of the sound impedance difference between the media and the type of the interface ${ }^{38}$. The received ultrasound waves are either in reflection or attenuation form. The latter one also known as transmission mode. The transducer in reflection or pulse-echo mode preforms both receiving and sending the sound waves. The received signals (waves) reflected from the wall of the pipeline or from imperfection in the walls like the scales deposit or corrosion pit. The resulted signal displayed with amplitude represents intensity of refection and distance which represent the arrival time of the reflected waves. In addition, the distance between the interfaces can be used to measure thickness of the scale by calculating time interval between the sent and reflected sound waves. In the latter type the transmitter sends ultrasound wave, but separated receiver detects the reflected signals after traveling through the medium. The reflected signals from both modes are detected, digitized and then transferred to a computer where the signals are analyzed. The detected signals are compared with some stored templates and database to monitor scale formation. A typical ultrasound technique is presented in Figure 2

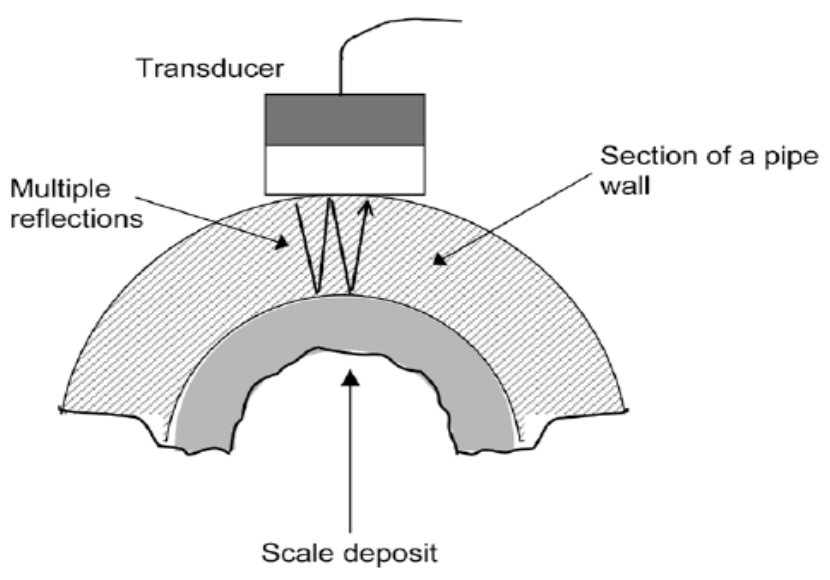

Figure 2. Ultrasound method for scale detection ${ }^{39}$.

wherein the outer surface of the pipeline there is a transducer. The probe receives a series of multiple echoes of diminishing amplitudes results from the reverberation of the sound wave through pipe walls ${ }^{39}$.

Ultrasound internal inspection can be also used to detect scale when the outside of pipeline is inaccessible. Illustration for typical setup for the ultrasonic system from the inside of the pipeline is presented in Figure $3^{40}$. Different from the previous system, the transducer is moving in a circular arc with the robot or pig moves through the pipe. In imaging the internal surface of pipelines, focused transducer is always used to produce a high lateral resolution when the distance between transducer

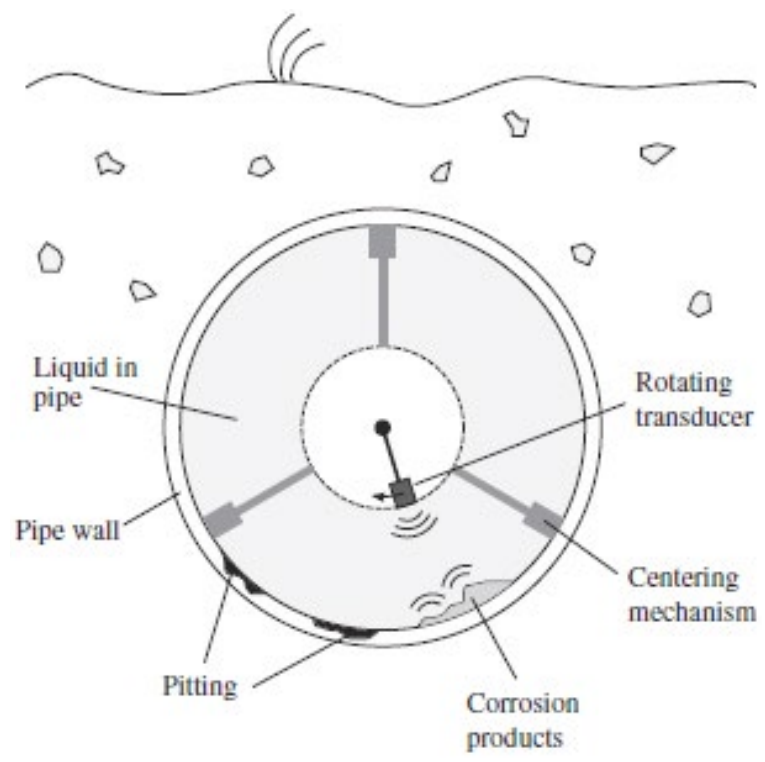

Figure 3. Internal ultrasound inspection system ${ }^{40}$. 
and pipe wall within its focus length. It also indicates that a reduction in lateral resolution could happen due to the changing in the distance. To solve the problem, Martin $\mathrm{H}$. Skjelvareid employed synthetic aperture focusing technique as well as Cylindrical Phase Shift Migration algorithm (CPSM). However, this method cannot be used to estimate the thickness and types of scale.

Conventional ultrasonic can't be directly used to quantify the scale amount. Two main reasons limited direct applicability of the technique. First, the speed of the sound within the deposit is unknown. Second the weak echoes results from deposits are covered by the strong reflected signals from pipe's walls ${ }^{38}$. A variety of computer models can be generated to tune the real weak signal to overcome strong reflected echoes and to compare it with stored database ${ }^{41}$. Gunarathne and Christidis demonstrated that the probability of identifying scale deposits is low if their sound characteristics (B-coefficient or velocity) are close to each other ${ }^{39}$. B coefficient is an important parameter for scale identification and it is related to the signal decay.

Yasser Qureshi and Gunarathne tried to generate artificial reference signals and simulate the process of sending and receiving sound wave between transducer and target objects using numerical computation model ${ }^{42}$. The simulated results shown B coefficient comforted to the experimental practice in the case of planer steel block with a thickness range of 5-10 mm. Less satisfied results were obtained for the steel samples which were immersed in oil. However, more research should be done to test the availability on other materials and scale deposits as well as on near-actual operation conditions of pipelines. Another approach was developed by. They prepared artificial neural networks (ANNs) system using a multi-layer perceptron neural network with three layers of neurons as microcontroller-based system ${ }^{39}$. The intelligent, hardware-based method was able to identify in situ mineral deposits like calcium carbonate, strontium sulfate and wax, which are common scale deposit in petroleum pipelines as well as marble and steel using data collected under laboratory condition. However, result for barium sulfate was not promising and need more fine refinements. In addition, instead of estimating the scale deposits based on only one parameter, B coefficient or sound velocity, the author fused both two sets of data to achieve a more accurate result compared with Yasser Qureshi's work.

In general, using ultrasound techniques has many advantages. It can measure the thickness of scales and the condition of the pipeline using high penetrating power with an online data system and remotely monitoring for scale formation ${ }^{43}$. The ultrasound system is nonhazardous for the work place nearby equipment and work wear. High sensitivity and great accuracy nondestructive techniques. Also for detection only one side of the pipe need to be accessible to attach the transducer. Portable and capable to estimate some types of scales.

At the same time ultrasound methods have some limitation and disadvantages. It's slow, and expensive method and it's very difficult to link it to the pipe wall with a fast moving pig ${ }^{28}$ Moreover, it is necessary to shut down the operation before running the inspection for cleaning purpose. Surface cleaning is required for the inspection to remove paints, insulations and loose scale that can't be measured. The cleaning process will waste a lot of time and affect the production process ${ }^{37}$. Also, some ultrasound systems are not sensitive to the presence of defects which mean if there are irregular or rough parts in the pipes due to the pits or insulation it will be difficult to examine. Some system showed that it is hard to detect scale when the pipeline steel thickness is big. ${ }^{1}$ Careful attention should be done for very thin materials and the whole measurement test should be applied by experience technicians with good knowledge to develop inspection procedures.

\section{Magnetic Flux Leakage (MFL)}

MFL tool started to be known in the 1950's and from that time on, it becomes one of the most commonly used tools for pipeline inspection besides ultrasound techniques ${ }^{44}$. The MFL method is based on the approach of magnetization the internal of the steel or ferromagnetic pipeline material and recording any change in the magnetic field. Under normal condition of clean pipeline, there will be no change in a magnetic field. However, in case of defect presence, a magnetic resistance will be developed by the defect area due to its lower permeability as compared to the pipe material. As a result, the magnetic flux will leak or be disturbed. This leakage is detected by an array of sensors that are placed between the poles of the magnet $^{45,46}$. The basic principle and component of MFL pig can be shown in Figure $4^{47}$.

MFL can be divided into three main types, standard/low, high resolution and extra high resolution $\mathrm{MFL}^{48}$. As indicated by the name, the main differences between these kinds are the degree of resolution 


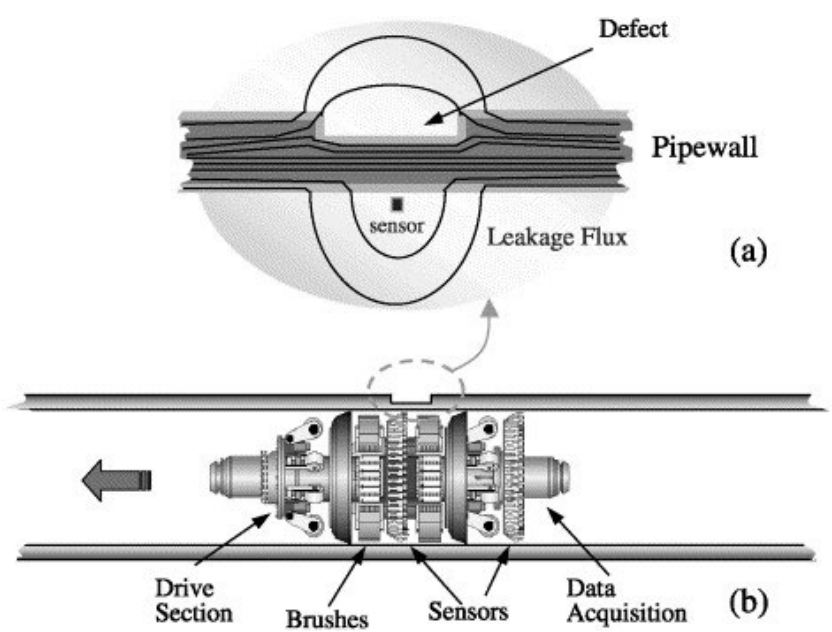

Figure 4. MFL pig components and principle ${ }^{47}$.

obtained and the number of sensors used. The best selection between these types can vary according to the required results. Generally, in order to detect the magnetic signals and to convert it to electric signals, MFL use different types of sensors. Among these different magnetic sensors, hall components and induction coils are the most frequently applied. Other sensors also exist, such as magnetic sensitive diodes and magnetic flux gates ${ }^{44}$. Each type of sensor has different range of sensitivity.

MFL is a nondestructive technique that provides an in-line inspection tool for oil and gas pipeline without being affected by the nature of the fluid inside the pipeline. It showed an advantageous in the case of buried or difficult to access pipeline. Also, it is more practical than an ultrasound tool in case of gas pipeline because it does not require a caustic coupling liquid existence ${ }^{49}$. This matured technology has been used successfully in many real applications, mainly using intelligent pig. MFL combines several advantages, including the high precision, simplicity of the structure and the reasonability of its price. It is useful in determining the location and detecting corrosion defects, leaks, loss of thickness (due to corrosion). In addition, MFL can provide qualitative information regarding the presence of different type of defect in the circumferential and axial directions of the pipe including pits, cracks, cavities and shrinkage ${ }^{47}$. Beside, MFL technique also proofs its ability in other applications such as pipeline wall thickness determination. However, it should be mentioned that this technique is not complete and it has several limitations that hinder its ultimate use. In order for MFL to detect the signal, the pipeline should be magnetized to saturation ${ }^{50}$. This means it will be affected by the pipeline thickness. In other word, it cannot be useful in the very thick pipeline or even small pipes. The use of internal corrosion sensor (ICS) is one of the developed techniques to allow the detection of internal corrosion without being affected by the pipe wall thickness as magnetic saturation is not required. Initial results show the high possibility of widening MFL applicability by using such method. Another disadvantageous could result from any magnetization remaining inside the pipe ${ }^{48}$. Generally, MFL requires a large number of analysis and the qualitative results are quite complicated and its interpretation depends on the experience of the operator. The quantitative information from this technique is still in early stages and requires a lot of developments. Despites its ability to detect different defect type, it cannot classify the shape of defects or differentiate between inner and outer defects. One of the recent studies by ${ }^{51}$, is addressing the latter problem by using weak magnetic field model since it will not only depend on the external magnetic field but also depend on the material magnetic moment. However, the influence of the pipe thickness and material on the results should be addressed first. Additional limitation of the magnetic flux leakage technique is that the material surface condition can influence the results. Dirt or deposits can increase the noise level and mask the real signal. As a result, cleaning can be essential before MFL use. It should be concluded from this point that MFL is not the best suitable techniques for detecting scale deposits in the pipeline. However, it was included in this review because in real application MFL pigs are equipped with brushes and magnets that is powerful enough to remove waxy residual unlike ultrasonic tools ${ }^{52}$.

\section{Radioactive Techniques}

Among the four known types of radioactivity (Figure 5), gamma and neutron are more involved in scale identification application due to their penetration ability ${ }^{53}$. Gamma ray is easier to detect than neutron ${ }^{54}$ and can be used in different ways, but generally it can be classified to either transmission, backscattering or gamma emission (radioactive tracers) principle. 


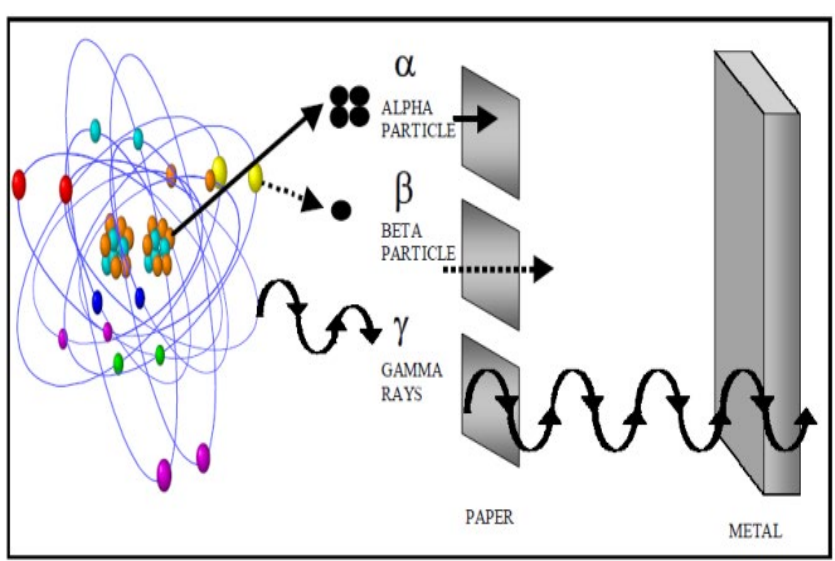

Figure 5. Radioisotopes ${ }^{53}$.

\subsection{Gamma Ray Interaction Methods}

\subsubsection{Gamma Ray Transmission}

Gamma ray transmission technique (Figure 6) ) $^{55}$ is another system for detecting scale inside the pipeline by providing a density profile of the studied pipe section. Cobalt- 60 and caesium-137 are the two commonly used radioactive sources. In light of higher energy, Cobalt-60 is always applied for pipeline with thick wall or big diameter. To the contrary, caesium-137 is used for thin or normal thickness wall's pipeline. The principle of this non-destructive method is explained through the Beers Lamberts' law ${ }^{56,57}$.

$$
I=I_{o} \cdot e^{-\mu \rho x}
$$

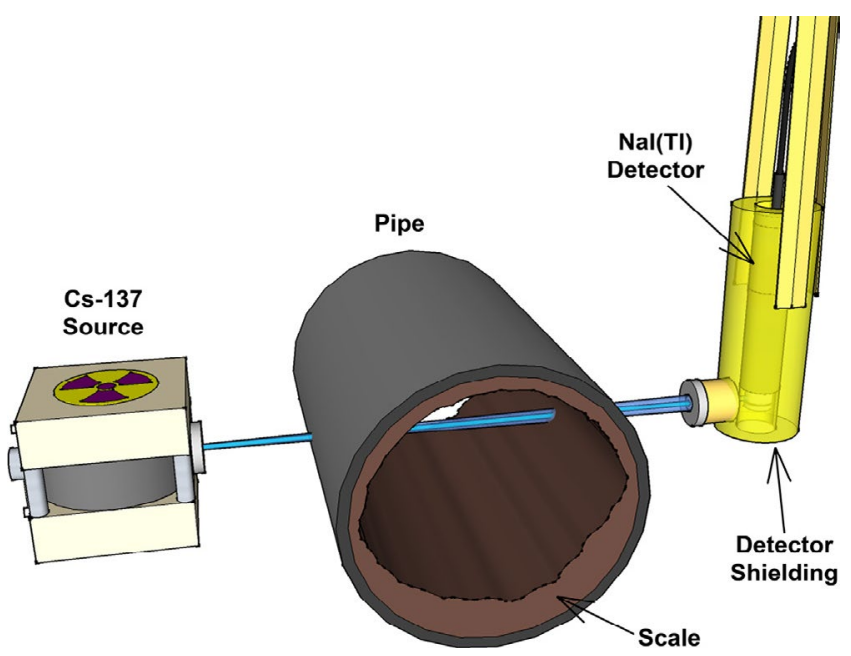

Figure 6. Setup for gamma transmission inspection ${ }^{55}$.
Where Io and I refer to the intensity of gamma ray initially and after adsorption. While, $\mu, \rho$ and $\mathrm{x}$ refer to radiation absorption coefficient (linear attenuation coefficient), density and thickness of the absorber, respectively.

When the low energy gamma ray from the source interact with the electrons of the materials inside the pipe, part of the radiation will be absorbed. This adsorption is due to different types of interaction, such as photoelectric, pair production and Compton scattering ${ }^{58}$. Generally, the decrease in radiation beam intensity, when compared with the original gamma ray intensity, can be related to the scale thickness. The difference in scale density and composition can result in different degree of adsorption. Recently, In ${ }^{55}$ reported the efficiency of using a gamma transmission in finding and quantifying the thickness of the scale conducted in oil exploration pipelines. Caesium-137 was used as the radioactive source and coupled with a $\mathrm{NaI}(\mathrm{Tl})$ scintillation detector. A mathematical model was also constructed based on the relation between transmitted gamma intensity and thickness of the scale. Given the known thickness of scale in the pipeline, the simulated transmitted intensity highly agreed with experimental results. However, through one profile testing, it is impossible to give the scale distribution in pipes. This can be solved by combining one more testing in different profile. Due to the limitation of the mathematical assumption, defects and pitting cannot be detected and their presence can affect the result. Besides, the properties of scale in real situation is not the same as assumed ideally in this paper which could also be threaten to the in situ analyzing.

It should be mentioned that despite using the same type of source, gamma ray, as used in radiography. The energy in this system has low dose and activity. As a result, Gamma transmission is safer and can be used with less distortion to the normal operation process. Other advantage beside the radioprotection is that small space is needed for this transmission technique again unlike radiography. Studies on using gamma ray for scale thickness quantification claimed high precision for using such system. However, the identification of the scale location is not possible by this method which can be one of the main limitations of gamma ray transmission ${ }^{55}$. Another limitation could be the unsuitability of using such method when the pipes are buried or difficult to access from both sides $^{56}$. 


\subsubsection{Dual and Triple Energy Spectral Gamma} Ray

This technique is another type of gamma ray attenuation, but quite different than the traditional gamma attenuation explained earlier. The main difference is that these new types don't depend on normally occurring radioactive material ${ }^{59}$. The operation started by using radioactive sources on one side of the investigated material such as barium source- $133^{15}$. Once the source emits gamma ray at different energy, the attenuation of gamma ray will be detected at two or three different energy levels using a detector positioned at the other side of the material. The main idea behind using these techniques in scale detection is that the atoms making up the scale are heavier than carbon, hydrogen and oxygen atoms of water and hydrocarbon, this scale presence will cause an increase in attenuation level ${ }^{20}$. Many field applications since 1994 have reported the robust use of Dual-energy-Venturi multiphase flow meter in the multiphase flow application to identify oil, gas and water fractions. Also, a group has reported the successful use of such flow meter in scale detection at two fields in the North Sea ${ }^{60}$. This measurement doesn't disturb the flow, allowing real time detection method at an early stage, especially by using ceramic windows, detection of very small scale deposits become possible. Using triple energy is another new technique presented group ${ }^{20}$. It reflected more robust and faster ability than dual energy use. These spectral gamma attenuation methods can provide several information about scale deposits, including nature, quantity, thickness as well as rate of accumulation. Additionally, this method is well established and can withstand harsh condition of high temperature and pressure.

The scale information is obtained based on measuring the ratio of high to low energy or by identifying the shift in spectral position with respect to reference points of the solution triangle ${ }^{15}$. Generally, the slope is used to identify the nature of the scale while the magnitude can be used to obtain the scale thickness. As can be seen this technique is one of the most powerful measurements for scale inspection, but it is still not the optimum solution due to the use of radioactive sources. Another issue is the portability of this device which is difficult due to the weight of shielding layer in the instruments. Also, gamma attenuation is affected by solid particle and dust presence. It is not applicable when the diameter of the pipe is large due to the high attenuation effect and generally require several measurements at different points to reflect the real situation of the pipe which can be difficult $t^{54}$.

\subsection{Neutron Interaction Methods}

Prompt gamma emission or alternatively known as neutron capture gamma ray is a common method for monitoring and identifying scales inside pipes ${ }^{61,62}$. In this method a neutron source is attached outside of the pipe providing neutrons that can interact with the materials inside the pipe. Upon this interaction, some of the neutron is adsorbed by the scale and characteristic gamma rays are emitted ${ }^{63}$. The intensity of this photon reflects the amount and thickness of the scale, while the energy can be used to identify the type of the scale. Several studies have been reported by al for using this technique in the identification of organic and inorganic scale thickness and type ${ }^{61-65}$. As an example $\mathrm{CaSO}_{4}$ and asphalt scale was identified by using ${ }^{241} \mathrm{Am} /{ }^{9} \mathrm{Be}$ source and high purity Ge gamma detector ${ }^{61,62}$.

The method proved its ability to provide simultaneous information about the type and amount of scale which is rarely possible by other methods. Also, it can scan large areas while requiring an access from one side ${ }^{61}$. However, some of the faced limitations that should be overcome is the low sensitivity, complicate set up and expensive equipment as compared to other techniques like neutron back diffusion ${ }^{65}$. It means that initial and early scale detection is not possible with the current technique. Another limitation is the longtime of analysis, which is not favored for real application. It was suggested to use higher energy source to make time shorter, but safety issue regarding the radiation generated and more field experiment should be investigated to confirm the applicability of this method.

Similar to the Capture gamma method in which a high energy, neutron source will penetrate the pipe $\left({ }^{252} \mathrm{Cf}\right.$ or $\left.{ }^{241} \mathrm{Am} / \mathrm{Be}\right)^{66}$. However, this technique is based on neutron back diffusion and detection by the neutron type detector such as $\mathrm{BF}_{3}$ slow neutron detector. The backward diffusion is mainly a result of neutron being slowed down as it scattered elastically with the components of the organic scale ${ }^{67}$. The detector is placed on the same side of the source which means it is better than gamma transmission techniques in term of one side access requirement ${ }^{56}$. This technique is less expensive, use a lower radiation dose than radiograph and uniquely portable, but the main drawback of such techniques is the sensitivity in the case 
of non-uniform insulation or curved surface. Also, interference from fluid signal can affect the scale signal.

It should be mentioned that neutron techniques such as back scattering or neutron capture gamma ray are suitable for only specific type of scale and they require calibration using suitable reference specimen which can hinder their ultimate commercial spread ${ }^{68}$.

\subsection{Tracer Injection Techniques}

Tracer technology involves the measurement of the deposits using tracers. The injected tracers usually are dye substances, but it can also be fluorescent or radioactive materials according to its selectivity with gas, oil or water phases69. Smaller amounts of tracers are injected into the pipeline the flow rates and the velocity of tracer between two detectors in the pipeline are detected and recorded. Using the Taylor dispersion model the amount of the deposits can be estimated where the tracer pulse velocity is compared with the tracer pulse at the entrance of the pipeline70. A simple measurement of tracer flow velocity can be obtained by dividing the time needed for the tracer pulse to reach the detector location from the starting point by the total distance traveled. Scale deposits not only reduce the internal diameter of the pipeline, but also increase its roughness which results in more walls rubbing.

The tracer concentration decreases as the pipeline roughness increases, which mean more deposit covering the internal diameter of the pipeline ${ }^{71}$. The change in the internal diameter of the pipeline will be related to the amount of the deposits. To get an accurate measurement and analysis for the scale deposition amount, suitable flow rate meter requires in addition to the careful choosing for the injection point and the tracer type $^{72}$. Tracer technology is widely used in many pipeline detection techniques because it is non-intrusive and real time evaluation system ${ }^{73}$. Also, it can estimate the scale deposits at any location along the pipe according to the detector place. The limitation of this technique is the requirement of a sensitive detectors and tracer material should have similar behavior to the investigated scale. The instrumentation or the detectors used will determent the accuracy of the whole analysis so it should be able to detect the tracer even at low concentration. Figure 7 presents the tracers response at injection point and at the exit point ${ }^{71}$.

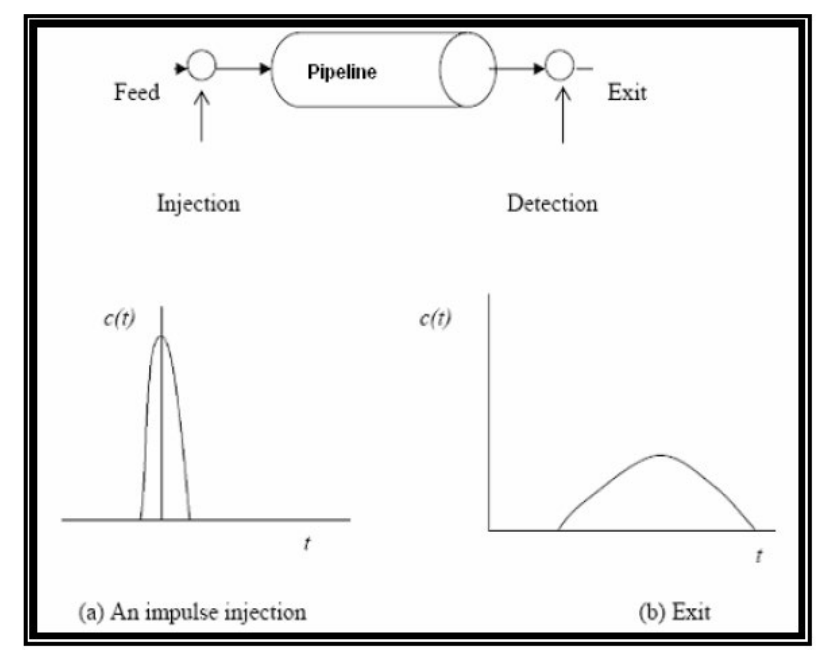

Figure 7. Tracers response at the injection point and outlet point ${ }^{71}$.

\subsection{Nuclear Attenuation Techniques}

Nuclear techniques can be used as a detection technique for scale deposits which naturally have radioactive components. This technique depends on a comparison of the post production gamma ray with pre-production logs. The limitation of this detection method is that it can't detect all the deposit types ${ }^{20}$.

Several nuclear techniques have been reported recently to provide in-situ detection and real time evaluation of the scale present in the pipeline ${ }^{74}$. Those techniques were capable to visualize the scale distribution by measuring the nuclear attenuation using the small device which is portable and capable to observe many scale deposit types. Until now all the work related to the nuclear attenuation investigation has been in laboratory scale ${ }^{75}$.

\section{Radiography Techniques}

Radiography is an old industrial inspection method that can be applied in-service pipeline to identify the thickness and composition of different scale. It is not only useful in identifying deposits, but also corrosion and different pipe defects $^{76}$. This non-destructive method consists of using electromagnetic radiation of high energy and short wavelength to penetrate the material under study. From the variation of radiation intensity due to the emitted radiation, radiographic image can be created. Radiography has two main radiation sources, Gamma and X-ray source ${ }^{77}$. Gamma ray is generated from isotopes, while $\mathrm{X}$-ray 
sources come from either radiogenic high vacuum tube or linear accelerators. The latter source has adjustable intensity and energy, according to the applied voltage and current. X-ray is more sensitive than Gamma ray but its sensitivity decreases as the pipe thickness increases. As a result, Gamma ray is more efficient in detecting pipe with large thickness ${ }^{78}$.

Radiography detectors were developed over the years. The initially sensitive photoelectric film was chemically treated to generate the image. Nowadays, this detecting method was replaced by digital or computed detectors that provide faster and better resolution image, allowing real time and in-situ monitoring of pipeline ${ }^{79}$.

Radiography using Gamma source is based on generating radiation from the disintegration of isotopes or unbalanced atomic nucleus. Initially, naturally occurring isotopes was known being discovered by latter on these naturally isotopes were replaced by man-made isotopes, which are preferred in term of cost and availability ${ }^{79}$. In addition, such artificial sources are stronger and can emit a variety of energy levels. For example, Selenium-75, Iridium-192, Cesium-137 and Cobalt-60 can provide an emission ray of different energy ranging from $220 \mathrm{KeV}$ to $1.33 \mathrm{MeV}$. The mostly used radiation in industry is Iridium-192. In comparison with X-ray source, Gamma ray is more stable in term of intensity and eliminating the need of additional electrical power or cooling device. Radiation danger and the lower resolution with the larger focal spots are still the main limitations of the effectiveness of this source in radiography. Additionally, since gamma ray results from isotopes they require frequent replacement which can increase the cost and hinder their application for ongoing monitoring ${ }^{80}$.

Radiography techniques can be divided into two types, tangential radiography and double wall radiography, the latter can be further divided into single and double image (Figure 8$)^{76,77}$. Generally, tangential apply the source rays at a tangential angle to the edge of the pipe while double wall radiography is based on densitometry of the radiograph. Double wall radiography covers larger area, but more subjective to errors, hence tangential are more preferred in the pipeline detection and thickness measurements. However, tangents are still limited by the high energy and radiation intensity required.

In general, several improvements have been done in the field of radiography in term of sources and image capturing method. Also, several studied report progress of these techniques portability and size. However, it is still

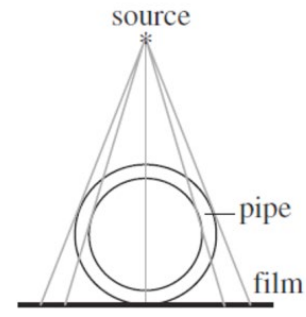

[A]

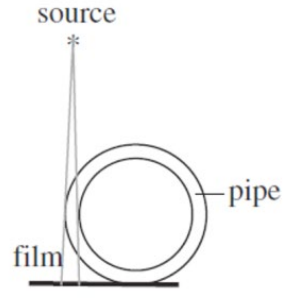

[B]

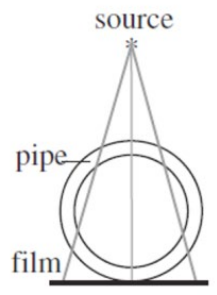

[C]
Figure 8. Radiography techniques: $[\mathrm{A}],[\mathrm{B}]$ tangential $[\mathrm{C}]$ double wall double image technique ${ }^{76,77}$.

considered expensive and slow techniques. Regardless of the source both principle of radiography, gamma and X-ray, require access from both sides which are not always possible ${ }^{78}$. Additionally, this technique is point study which reflects only small area from pipeline situation. Among the disadvantages, radiation hazard creates a huge concern for field application. This mainly because the high energy dose will require restriction on the employee access and can be impractical for operational production.

\section{Tomography}

Tomography is a real time imaging technique that has gained a wide attention in oil and gas industry over the recent years. X-ray, attenuated total reflection Fourier transform infrared (ATR-FTIR), NMR and gamma ray are some examples of the different available tomography techniques. Generally, the basic principle of tomography is to produce a density mapping or imaging as shown in Figure 9 by exposing the material of interest to

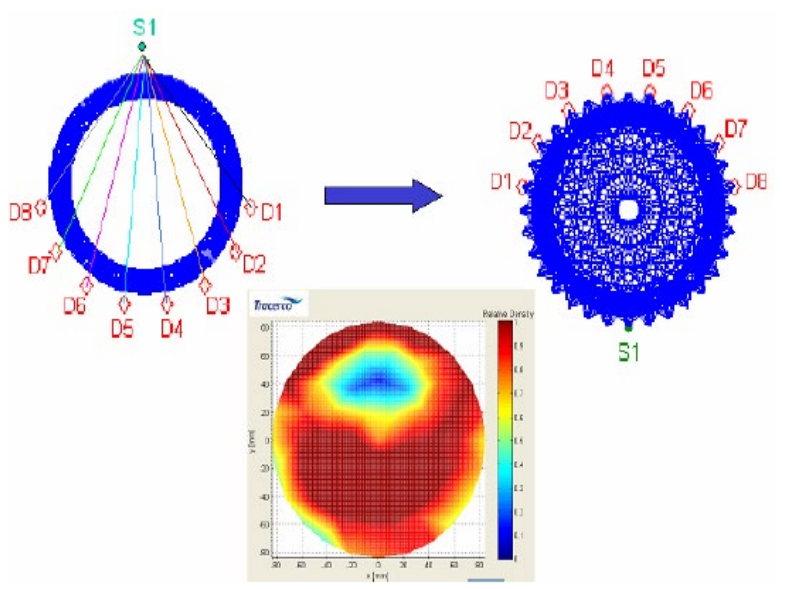

Figure 9. Principle of tomography scanning, S: source, D: detector $^{73}$. 
a radiation source or electromagnetic waves or any other physical stimulus. Then from the object response and by using computers and mathematical models which called tomography reconstruction, the internal material distribution can be visualized ${ }^{73}$.

Different tomography techniques have shown potential in pipeline monitoring and deposit detection especially wax detection. For example, Dan Benson and his team discussed some trials for using gamma ray tomography and fluid distribution in pipeline was obtained under different conditions ${ }^{73}$. The results of tomography scans give good indication about the effectiveness of this technique where the image resolution was better than expected. In addition, Yvette Shaan investigated the possible use of portable gamma ray for detecting corrosion under insulation of pipeline ${ }^{81}$. This assumption gives rise to a potential to monitor corrosion in areas that is hard to detect. To support it, certain experiments should be done. Also, Jongbum Kim studied the use of the clump-on portable gamma tomography system through stimulation study ${ }^{82}$. These results can be encouraging for applying the same principle for scale and other deposit detection. Several researchers have studied other tomography techniques such as NMR and ATR-FTIR for asphaltine deposits monitoring ${ }^{83,84}$. However, further investigations should be conducted to understand and fully optimize this technique before it can be used in industrial application. Electrical tomography, mainly electrical capacitance tomography (ECT) is a promising tomography process that was used as a real-time technique for monitoring wax deposition in pipelines ${ }^{85}$. This method depends on the permittivity or conductivity of the internal media. It has an advantage over the other tomography techniques since it does not use ionizing radiation. From an industrial point of view, ionizing radiation is not favored for large scale application due to their cost. Another advantage of ECT is its fast response.

Tomography techniques have several advantages such as being nondestructive, so it can be applied in online monitoring of pipelines without affecting the normal process. Also, it can provide 3D imaging and have shown great results in many lab scale studies. It should be mentioned that tomography is a signal location measurement, in other word to get an imaging of pipeline cross-section; multiple measurement should be taken by moving the source around the pipeline circumference ${ }^{86}$. Another limitation is related to the image quality. Low image resolution is often encountered which make it more difficult to distinguish around the phase boundary of the materials. The use of some tomography techniques such as gamma and $\mathrm{X}$-ray can be considered as an expensive source of imaging.

\section{Pig Technology}

Pig is a device that travels along the inside of the pipeline while performing different tasks ranging from visualizing the inside of the pipeline, cleaning or inspections ${ }^{87}$. The name itself is an acronym of "Pipeline Inspection Gauge" or originated from the sound created by these devices ${ }^{88}$. Pigs can be classified into different types according to the intend application. Generally, pigs come in different shapes and sizes, allowing them to be suitable for the pipeline size and the intended purpose, but they should be flexible around bents and small area of the pipes. The pig has gained considerable attention over years since they are very useful in managing the oil and gas pipeline integrity, traveling over long pipeline distances and overcoming a lot of obstacles that can be faced by conventional inspection methods ${ }^{89}$. In addition to the huge cost that can be saved by the early warning from using pigs, stopping the operation is not required during pigging which is an additional advantage from economical point of view. With respect to scale deposit and corrosion problem, pig offer two main jobs: cleaning and inline inspection through intelligent or smart pigs ${ }^{90}$.

Intelligent pigs are equipped with sensors, electronic instrumentation and data processing allow them to trace any defects and map the inside of the pipe with great precision while locating and recording any damage, corrosion or scale deposits such as wax or lime scale. There are two main types of sensors that are commonly applied in industry, magnetic flux leakage and ultrasound, but $90 \%$ of pig inspection relying on MFL (Figure 4) ${ }^{45,90}$. There are commonly known as metal loss pig as they provide information about any metal loss by corrosion and stress related cracking or other defects using sensors that can withstand harsh conditions. Also, some intelligent pigs are optical pigs that are equipped with camera or laser ${ }^{91}$.

Normally smart pigs are proceeded by another pig type called gauge pig that ensure the safety of the intelligent pigs by using a thin metal plate to check the minimum diameter of the pipe so the pig will not stick inside the pipe. The second classification of intelligent pig is 
geometry pig. These pigs have less number of sensors, but provide information about the internal geometry of the pipeline ${ }^{87,89}$. Scale thickness pig allows measuring the thickness of deposits and their distribution inside the pipeline.

The other classification is cleaning pigs that are used on a regular basis to ensure continuous pipe flow. It is equipped with different brushes, scrapers. Also, there is pig type with more aggressive cleaning tools such as carbide pins or blades ${ }^{92}$. They are difference in their size, hardness and equipment in order to suit the intended location, pipe material and the amount and hardness of the deposits. This cleaning is efficient to remove wax; paraffin, scale and hydrocarbon build up as it scraps them from the wall and carry them out of the pipe. Many Pipeline operations, conduct pigging as part of their routine maintenance. Addition of magnet to these pigs can aid in removing ferrous debris. Studded foam pigs and pin wheel pigs are two of the commonly used cleaning pigs ${ }^{52}$.

Foam pig is made of materials such as polyethylene, polyurethane or polypropylene rubber ${ }^{92}$. They are jellylike structured and are formulated on the site after being shipped in mold. It has limited life since it is biodegradable, but it can do a great job in case of large deposit presence. Generally, they are available in different density and normally the operation starts with using soft type followed by more firm and aggressive type as required by the pipe condition ${ }^{89}$. The main idea of foam is to avoid deposit build up by keeping them in suspension ahead of the pig and it can be combined with other chemicals such as corrosion inhibitor.

Gel pig is another type of pig that can remove debris and reduce wear of the pig as a good alternative of mechanical pig. Also, it has the advantage of easy extrusion. The higher load the debris, the higher viscosity and yield point are required in the type of gel used to keep the debris in suspension until removed. Successful application of gel pig was recorded in different countries such as Saudi Arabia, Nigeria and North Sea and America ${ }^{93}$. However, they are not as useful in dry pipe and can cause some problems in gas pipeline such as gas cutting. Besides its use in debris removal, gel pig can be used as separator, corrosion inhibitor applying and drying.

\section{Comparisons}

Scale deposits are organic and inorganic salts precipitate inside the pipeline walls and pumps, which affect the process of industrial operations. This reviews outlined some scale investigation techniques with highlighting its instrumentation and advantages (Table 2). Due to the technical development, relatively cheap, and sensitive devices for on-site analysis can be now constructed. The majority of industrial inspections depend on physical investigation or what's known as visual inspection is used to estimate the presence of scale. However, it is unable to give detailed information about scale. Besides, it's not accurate method and consumes a lot of time. At

Table 2. Comparison of different methods in scale measurement

\begin{tabular}{|c|c|c|c|c|c|c|}
\hline & \multicolumn{4}{|l|}{ Scale information } & \multicolumn{2}{|c|}{ Instrument information } \\
\hline & 1 & 2 & 3 & 4 & 5 & 6 \\
\hline & $\begin{array}{l}\text { Types can be detected } \\
\text { ( inorganic /organic / } \\
\text { corrosion defects) }\end{array}$ & $\begin{array}{l}\text { Identify } \\
\text { composition of } \\
\text { scale? }\end{array}$ & $\begin{array}{l}\text { Identify } \\
\text { location of } \\
\text { scale? }\end{array}$ & $\begin{array}{l}\text { Identify } \\
\text { thickness of } \\
\text { scale? }\end{array}$ & $\begin{array}{l}\text { In-situ } \\
\text { or offline } \\
\text { monitoring }\end{array}$ & $\begin{array}{l}\text { Can be used in } \\
\text { buried pipes? }\end{array}$ \\
\hline Conventional & $\mathrm{X}$ & $\mathrm{X}$ & $\mathrm{X}$ & $\mathrm{X}$ & offline & $\checkmark$ \\
\hline Eletrochemical & inorganic & $\mathrm{X}$ & $\mathrm{X}$ & $\mathrm{X}$ & offline & not mentioned \\
\hline Sensor & inorganic & $\mathrm{X}$ & $\mathrm{X}$ & DTS can & in-situ & not mentioned \\
\hline Ultrasound & inorganic /organic & $\mathrm{X}$ & $\checkmark$ & $\checkmark$ & in-situ & $\checkmark$ \\
\hline MFL & corrosion defects & $\mathrm{X}$ & $\checkmark$ & $\checkmark$ & in-situ & $\checkmark$ \\
\hline Radioactive & inorganic /organic & * & Tracer can & $\checkmark$ & in-situ & $\mathrm{X}$ \\
\hline Radiography & all & $\checkmark$ & $\checkmark$ & $\checkmark$ & in-situ & $\mathrm{X}$ \\
\hline Tomography & all & $\checkmark$ & $\checkmark$ & $\checkmark$ & in-situ & $\mathrm{X}$ \\
\hline
\end{tabular}

Note: $*$ neutron capture $\lambda$-ray method and dual/triple energy spectral $\lambda$-ray method can be used to identify the composition of formed scale 
the same time, there are many other techniques were able to detect scale, but couldn't differentiate between types or gave quantitative information about the formed type, electrochemical methods and sensor (except DTS), for example. Though, these two methods are good at estimating in organic scale formation at early stage under certain simulated field conditions. Among which, fiber optics are a flexible and a very sensitive tool that can detect small change in refractive index due to the formation of scale in the pipeline. As a result, there is a huge interest in using sensor which is based on fiber optics to detect scale. The sensor can be small in size, which make it more convenient to be used and at the same time it doesn't need any high energy waves. By contrast, ultrasound techniques can provide information as location and thickness. It is nonhazardous for the working place and can be used either outside or inside the pipeline through an internal inspection system. As for MFL, it is futile in determining especially corrosion defects in oil and gas pipelines. In addition, using some method like radioactive, radiography or tomography was impossible to be applied in buried pipelines. Due to the use of radioactive sources (except ECT), it is harmful to workers and environment where extra shielding is needed. However, much more detailed information can be obtained. Comparing these three methods, radioactive needs less energy but cannot analyze defects or pitting inside the pipe wall whereas the other two can provide internal imaging of the pipe at the cost of high energy sources.

Whilst not mentioned in detail here, the author would like to point out that to date there has been no development of Raman Spectroscopy ${ }^{94}$ as a means of scale identification. There is no room to discuss it in detail within this review; however as a remote sensing method of scale identification it is highly effective. Raman imaging is now available, and so it is only a matter of time before this technique is miniaturized and mounted on a PIG, providing the ability to map the internal scale deposits.

\section{Conclusions}

In the light all pre-existing and competing technologies, we feel that there is a gap in the market, whereby a new nondestructive method should be proposed to detect and identify scale deposits in the pipeline at early stages. Raman microscopy is a well-known system for identifying scale deposits, but to date has not been used for in-line scale inspection. The effectiveness of using a portable Raman technique as a real time monitoring system can have a great potential for the future of pipeline monitoring system.

\section{Acknowledgements}

This work is supported by the Chemistry Department, Khalifa University of Science and Technology, Petroleum Institute Campus and by ADNOC Gas Sub Committee, Research and Development Project 14703. The author declares that there is no conflict of interest regarding the publication of this paper.

\section{References}

1. Almutairi FH, Davies DR. Detection of scale deposition using distributed temperature sensing. SPE International Oilfield Scale Conference. Society of Petroleum Engineers. 2008; p. 1-13. crossref.

2. Alhammadi K, Bouchalkha A, Sowwan S. Scale detection using light sensing technique. IEEE Jordan Conference on Applied Electrical Engineering and Computing Technologies (AEECT). 2015; p. 1-4. crossref.

3. Shar AH, Ahmad T, Bregar UB. Scale buildup, its detection and removal in high temperature gas wells of miano field. SPE Production and Operations Conference and Exhibition, Society of Petroleum Engineers. 2010; p. 1-15.

4. Okazaki T. Fundamental Study on the Development of Fiber Optic Sensor for Real-time Sensing of CaCO3 Scale Formation in Geothermal Water. Analytical Sciences. 2015; 31(3):177-83. crossref. PMid:25765379.

5. Haghtalab A. Investigation of the Precipitation of Calcium Sulfate in Porous Media: Experimental and Mathematical Modeling. Chemical Engineering Communications. 2015; 202(9):1221-30. crossref.

6. Hon VY, Khor SF. Coupled Thermodynamic-Flow Model Simulator for Inorganic Scale Deposition Calculation. Abu Dhabi International Petroleum Exhibition and Conference, Society of Petroleum Engineers. 2010; p. 1-5. crossref.

7. Stamatakis E, Stubos A, Muller J. Scale prediction in liquid flow through porous media: A geochemical model for the simulation of $\mathrm{CaCO} 3$ deposition at the near-well region. Journal of Geochemical Exploration. 2011; 108(2):115-25. crossref.

8. Hinrichsen CJ. Preventing Scale Deposition in Oil Production Facilities: An Industry Review. CORROSION 98, NACE International. 1998; p. 1-29.

9. Crabtree M. Fighting scale-removal and prevention. Oilfield Review. 1999; 11(3):30-45. 
10. Bin Merdhah AB, Yassin AAM, Muherei MA. Laboratory and prediction of barium sulfate scaling at high-barium formation water. Journal of Petroleum Science and Engineering. 2010; 70(1):79-88.

11. Tsochatzidis NA, Maroulis KE. Methods help remove black powder from gas pipelines. Oil and Gas Journal. 2007; 105(10):52.

12. El-Sherik A. Managing black powder in sales-gas transmission pipelines. Journal of Pipeline Engineering. 2016; 15(1):19-24.

13. Khan TS, Al-Shehhi MS. Review of black powder in gas pipelines-An industrial perspective. Journal of Natural Gas Science and Engineering. 2015; 25:66-76. crossref.

14. Bai Y, Bai Q. Subsea engineering handbook. Gulf Professional Publishing. 2012; p. 1-956.

15. Bertrand B, Segeral G, Moksnes PO. Detection and Identification of Scales Using Dual Energy/Venturi Subsea or Topside Multiphase Flow Meters. Offshore Technology Conference. 2001; p. 1-10. crossref.

16. Merdhah AB, Yassin AZ. Scale formation due to water injection in Malaysian sandstone cores. American Journal of Applied Sciences. 2009; 6(8):1531-8. crossref.

17. Feasey ND. Field Experiences with a Novel Near Real Time Monitor for Scale Deposition in Oilfield Systems. CORROSION 2000, NACE International. 2000; p. 1-14.

18. Smith J. Real-time and in-situ detection of calcium carbonate scale in a west Texas oil field. SPE Production \& Facilities. 2004; 19(02):94-9. crossref.

19. Emmons D. On-site, near-real-time monitoring of scale deposition. SPE annual technical conference, Society of Petroleum Engineers. 1999; p. 1-16. crossref.

20. Poyet JP, Segeral G, Toskey E. Real-Time Method for the Detection and Characterization of Scale. International Symposium on Oilfield Scale, Society of Petroleum Engineers. 2002; p. 1-11. crossref.

21. Aiyejina A. Wax formation in oil pipelines: A critical review. International Journal of Multiphase Flow. 2011; 37(7):67194. crossref.

22. Amjad Z, Demadis KD. Mineral Scales and Deposits: Scientific and Technological Approaches. Elsevier. 2015; p. 1-784.

23. Neville A, Hodgkiess T, Morizot A. Electrochemical assessment of calcium carbonate deposition using a rotating disc electrode (RDE). Journal of Applied Electrochemistry. 1999; 29(4):455-62. crossref.

24. Morizot A, Neville A. A novel approach for monitoring of $\mathrm{CaCO} 3$ and $\mathrm{BaSO} 4$ scale formation. International Symposium on Oilfield Scale, Society of Petroleum Engineers. 2000; p. 1-6. crossref.

25. Englander H. Conductometric Measurement of Carbonate Scale Deposition and Scale Inhibitor Effectiveness. Journal of Petroleum Technology. 1975; 27(07):827-34. crossref.
26. Boerkamp M, Lamb D, Lye P. An intrinsic exposed core optical fiber sensor as a quantitative surface crystallization monitoring sensor. Sensors and Actuators B: Chemical. 2013; 177:964-9. crossref.

27. Philip-Chandy R, Scully P, Thomas D. A novel technique for on-line measurement of scaling using a multimode optical fibre sensor for industrial applications. Sensors and Actuators B: Chemical. 2000; 71(1):19-23. crossref.

28. Boerkamp M, Lamb D, Lye P. Using an intrinsic, exposed core, optical fibre sensor to quantify chemical scale formation. Journal of Physics: Conference Series. IOP Publishing. 2007; 7:1-8.

29. Boerkamp M, Lamb D, Lye P. Investigating surface crystal growth using an intrinsic exposed core optical fibre sensor. Sensors and Actuators B: Chemical. 2011; 157(2):581-5. crossref.

30. Abderrahmane S. An optical fibre corrosion sensor with an electroless deposit of Ni-P. Sensors and Actuators B: Chemical. 2001; 75(1):1-4. crossref.

31. Smith JK. Real-time on-line sensing and control of mineral scale deposition from formation fluids. Google Patents. 2005; p. 1-11.

32. Couet B, Jones TGJ. Deposition monitoring system. Google Patents. 2005; p. 1-22.

33. Adebayo AR, Al-Yousef HY, Mahmoud M. An experimental investigation of the use of combined resistivity and temperature logs for scale monitoring in carbonate formations during $\mathrm{CO} 2$ sequestration. Journal of Energy Resources Technology. 2015; 137(3):032202. crossref.

34. Shih WY. A dual-probe approach for evaluation of gypsum crystallization in response to antiscalant treatment. Desalination. 2004; 169(3):213-21. crossref.

35. Hasson D. Mechanism of calcium carbonate scale deposition on heat-transfer surfaces. Industrial \& Engineering Chemistry Fundamentals. 1968; 7(1):59-65. crossref.

36. Morizot A, Neville A. Barium sulfate deposition and precipitation using a combined electrochemical surface and bulk solution approach. Corrosion. 2000; 56(6):638-45. crossref.

37. Gamidi SH. Non Destructive Testing of Structures. Indian Institute of Technology. Bombay. 2009.

38. Gunarathne G, Keatch R. Novel techniques for monitoring and enhancing dissolution of mineral deposits in petroleum pipelines. Ultrasonics. 1996; 34(2):411-9. crossref.

39. Christidis K, Gunarathne GP, Peteineri K. Intelligent instrumentation for identification of scales in petroleum pipelines in situ. Transactions of the Institute of Measurement and Control. 2012; 35(4):457-63. crossref.

40. Skjelvareid $M H$, Birkelund Y, Larsen Y. Internal pipeline inspection using virtual source synthetic aperture ultrasound imaging. NDT \& E International. 2013; 54:151-8. crossref. 
41. Gunarathne G, Ezhou Q, Christidis K. Ultrasonic feature extraction techniques for characterisation and quantification of scales in petroleum pipelines. IEEE Ultrasonics Symposium. Proceedings (Cat. No. 98CH36102). 1998; 1:859-64. crossref.

42. Gunarathne GP, Qureshi Y. Development of a synthetic A-scan technique for ultrasonic testing of pipelines. IEEE Transactions on Instrumentation and Measurement. 2005; 54(1):192-9. crossref

43. Gunarathne G. Online monitoring and characterisation of mineral deposits in petroleum pipelines. On-line Monitoring Techniques for the Off-Shore Industry (Ref. No. 1999/143), IEE Seminar on IET. 1999. crossref.

44. Shi Y. Theory and Application of Magnetic Flux Leakage Pipeline Detection. Sensors. 2015; 15(12):31036-55. crossref. PMid:26690435 PMCid:PMC4721765.

45. Carvalho A. MFL signals and artificial neural networks applied to detection and classification of pipe weld defects. NDT \& E International. 2006; 39(8):661-7. crossref.

46. Saavedra CJ, Prada SR. Sensitivity analysis of a magnetic circuit for non-destructive testing by the magnetic flux leakage technique. III International Congress of Engineering Mechatronics and Automation (CIIMA). 2014; p. 1-5.

47. Afzal M, Udpa S. Advanced signal processing of magnetic flux leakage data obtained from seamless gas pipeline. NDT \& E International. 2002; 35(7):449-57. crossref.

48. Bickerstaff R. Review of sensor technologies for in-line inspection of natural gas pipelines. Sandia National Laboratories, Albuquerque. 2002.

49. Zhang Y, Yan G. Detection of gas pipe wall thickness based on electromagnetic flux leakage. Russian Journal of Nondestructive Testing. 2007; 43(2):123-32. crossref.

50. Gloria N. Development of a magnetic sensor for detection and sizing of internal pipeline corrosion defects. NDT \& E International. 2009; 42(8):669-77. crossref.

51. Liu B. Weak magnetic flux leakage: A possible method for studying pipeline defects located either inside or outside the structures. NDT \& E International. 2015; 74:81-6. crossref.

52. Stewart M. Surface Production Operations: Volume III: Facility Piping and Pipeline Systems. Gulf Professional Publishing. 2015; p. 1-1090.

53. Hood T. Verification of Flare Line Flows and Pipeline Deposit Measurement Using Non-Intrusive Radioisotope Technology. Society of Petroleum Engineers. 2004; p. 1-6. crossref.

54. Osman A, Abdel-Monem A, El Abd A. Measurement of void fraction in pipes by neutron backscattering imaging technique. Indian Journal of Pure \& Applied Physics (IJPAP). 2015; 52(7):437-43.

55. Oliveira DF. Gamma transmission system for detection of scale in oil exploration pipelines. Nuclear Instruments and Methods in Physics Research Section A: Accelerators, Spectrometers, Detectors and Associated Equipment. 2015; 784:616-20. crossref.

56. von Olearius S. Pipeline Assurance Using Radioisotope Applications to Go from Installation over Inspection to Overhauling. In 4th Pipeline Technology Conference. EITEP Institute 2011. 2009.

57. Song WJ, Lee SH, Jeong HD. Development of deposit detection system in pipelines of the steelworks using Cs 137 gamma rays. 34th Annual Review of Progress in Quantitative Nondestructive Evaluation, AIP Publishing. 2008; p. 1374-80. PMid:18376866.

58. Mandal D. Quality of fluidization in gas-solid unary and packed fluidized beds: An experimental study using gamma ray transmission technique. Powder technology. 2012; 226:91-8. crossref.

59. Bamforth S. Revitalizing Production Logging. Oilfield Review. 1996; 8(4):44-60.

60. Jordan M. Inhibition of Lead and Zinc Sulphide Scale Deposits Formed during Production from High Temperature Oil and Condensate Reservoirs. SPE Asia Pacific Oil and Gas Conference and Exhibition, Society of Petroleum Engineers. 2000; p. 1-12.

61. Abdul-Majid S. Simultaneous Determination of Iron Pipe Wall and Scale Thicknesses by Prompt Gamma Emission Method. Proceeding 3rd Middle East Nondestructive Testing Conference and Exhibition. 2005; p. 1-10.

62. Abdul-Majid S, Dawood U. Neutron-capture gamma-ray technique for scale identification inside pipes. Desalination. 1989; 75:199-210. crossref.

63. Abdul-Majid S, Melaibari A, Malki B. Hydrocarbon scale deposits measurements by neutron moderation and capture gamma methods. Nuclear Instruments and Methods in Physics Research Section B: Beam Interactions with Materials and Atoms. 1996; 119(3):433-7. crossref.

64. Abdul-Majid S. Determination of wax deposition and corrosion in pipelines by neutron back diffusion collimation and neutron capture gamma rays. Applied Radiation and Isotopes. 2013; 74:102-8. crossref. PMid:23410615.

65. Abdul-Majid S. Determination of scale thickness and general and localized metal removal in desalination plants by the gamma-ray interaction method. Desalination. 1993; 91(1):35-49. crossref.

66. Alami R, Bensitel A. Radioisotope Technology as Applied to Petrochemical Industry. INTECH Open Access Publisher. 2012; p. 1-318. crossref.

67. Abdul-Majid S. Applications of neutron back-diffusion technique for wall thickness and scale measurements at desalination or chemical plants. Desalination. 1993; 94(1):101-7. crossref. 
68. Harara W. Deposit thickness measurement in pipes by tangential radiography using gamma ray sources. Russian Journal of Nondestructive Testing. 2008; 44(11):796-802. crossref.

69. Authority ND. Drilling Fluid Tracers - Review and update of industry experience and issues for RWMD site characterisation programme. NDA-RWMD, Nuclear Decommissioning Authority Report. 2011; 1(2):1-89.

70. Singh SK, Beck M. Dispersion coefficient of streams from tracer experiment data. Journal of Environmental Engineering. 2003; 129(6):539-46. crossref.

71. Ebenezer SA, Gudmundsson J. Tracer Behaviour in Pipelines with Deposits and Analysis of Natural Gas Pressure Functions. Diploma, Norwegian University of Science and Technology, Norway. 2006.

72. Bischoff K. Theory of tracer flow. Fall Meeting of the Society of Petroleum Engineers of AIME, Society of Petroleum Engineers. 1963; p. 1-16.

73. Benson D. Non-intrusive Pipeline Inspection Techniques for Accurate Measurement of Hydrates and Waxes within Operational Pipelines. Offshore Europe, Society of Petroleum Engineers. 2007; p. 1-6. PMid:17612470.

74. Stamatakis E. Calcite scale prediction at the near-well region: A radiotracer approach. EPJ Web of Conferences. 2013; 50:1-6. crossref.

75. Stamatakis E. Scale Detection in Geothermal Systems: The use of nuclear monitoring techniques. Launching Conference of the European Project: Enhanced Geothermal Innovative Network for Europe (ENGINE), France. 2006; p. 1-6. PMid:16533571.

76. Edalati K. The use of radiography for thickness measurement and corrosion monitoring in pipes. International Journal of Pressure Vessels and Piping. 2006; 83(10):73641. crossref.

77. Zirnhelt J, Einav I, Infanzon S. Radiographic evaluation of corrosion and deposits: An IAEA Co-ordinate Research Project. 3rd PAN American Conference for Non Destructive Testing-PANNDT, Brazil. 2003; p. 1-10.

78. Fengqi $H$. Validation of protocols for corrosion and by deposit determination in pipes by radiography. Development of protocols for corrosion and deposits evaluation in pipes by radiography. 2005; p. 1-37.

79. Galbraith JM, Williamson GC, Creech M. Advances in Pipeline Radiography. CORROSION 2008, NACE International, USA. 2008; p. 1-7. PMid:18215293 PMCid:PMC2244639.

80. Denys R, Pipeline Technology: Proceedings of the 3rd International Pipeline Technology Conference. Brugge, Belgium, Gulf Professional Publishing. 2000; 1:1-1324.
81. Susiapan YSL. Portable gamma-ray tomography instrumentation for investigating corrosion under insulation of pipelines. WSEAS International Conference, World Scientific and Engineering Academy and Society. 2009; p. 1-4.

82. Kim J. A feasibility study on gamma-ray tomography by Monte Carlo simulation for development of portable tomographic system. Applied Radiation and Isotopes. 2012; 70(2):404-14. crossref. PMid:22079959.

83. Miknis FP. NMR imaging studies of asphaltene precipitation in asphalts. Fuel. 1998; 77(5):399-405. crossref.

84. Gabrienko AA. Chemical visualization of asphaltenes aggregation processes studied in situ with ATR-FTIR spectroscopic imaging and NMR imaging. Journal of Physical Chemistry C. 2015 ; 119(5):2646-60. crossref.

85. Mei ILS. Real-time monitoring and measurement of wax deposition in pipelines via non-invasive electrical capacitance tomography. Measurement Science and Technology. 2015; 27(2):025403. crossref.

86. Asseln B. On-line Surveys within Operational Pipelines Prior to Cleaning to Determine the Location and Amount of Deposits. 3rd Pipeline Technology Conference 2008. EITEP Institute. 2011; p. 1-11.

87. Davidson R. An introduction to pipeline pigging. Pigging Products and Services Association. 2002; p. 1-12. PMCid:PMC131009.

88. Nguyen TT. Speed control of PIG using bypass flow in natural gas pipeline. IEEE International Symposium on Industrial Electronics Proceedings (Cat. No.01TH8570). 2001; 2:863-8.

89. Reed C, Robinson AJ, Smart D. Techniques for monitoring structural behaviour of pipeline systems. American Water Works Association, USA. 2004; p. 1-246. PMCid:PMC1069065.

90. Kishawy HA, Gabbar HA. Review of pipeline integrity management practices. International Journal of Pressure Vessels and Piping. 2010; 87(7):373-80. crossref.

91. Valland A. Steel pipeline-state of the art for internal condition monitoring and inspection technologies. MARINTEK Norwegian Marine Technology Research Institute. 2010; p. 83.

92. Tiratsoo JN. Pipeline pigging technology. Gulf Professional Publishing. 1992; p. 1-460.

93. Uzu O, Napier R, Ngwuobia K. Gel pig technology applications in pipeline servicing. Nigerian Annual International Conference and Exhibition, Society of Petroleum Engineers. 2000. crossref.

94. Rostron P, Gerber S, Gerber D. Raman Spectroscopy, a Review. International Journal of Engineering and Technical Research (IJETR). 2016; 6(1):1-15. 